\title{
Perioperative outcomes following radical prostatectomy for patients with disseminated cancer: An analysis of the National Surgical Quality Improvement Program database
}

\author{
Raj Satkunasivam, MD;' Christopher J.D. Wallis, MD;1 James Byrne, MD;2 Azik Hoffman, MD; ${ }^{1}$ \\ Douglas C. Cheung, MD; Girish S. Kulkarni, MD; Avery B. Nathens, MD; ${ }^{2}$ Robert K. Nam, MD'
}

'Division of Urology, Department of Surgery, Sunnybrook Health Sciences Centre, University of Toronto, Toronto, ON, Canada; 2Division of General Surgery, Department of Surgery, Sunnybrook Health Sciences Centre, University of Toronto, Toronto, ON, Canada

Cite as: Can Urol Assoc J 2016;10(11-12):423-9. http://dx.doi.org/10.5489/cuaj.3939

\section{Abstract}

Introduction: We sought to determine whether patients undergoing radical prostatectomy (RP) in the context of disseminated cancer have higher 30-day complications.

Methods: We conducted a retrospective cohort study of the National Surgical Quality Improvement Program (NSQIP) database. Men undergoing RP (from January 1, 2005 to December 31, 2014) for prostate cancer were identified and stratified by presence $(n=97)$ or absence $(n=27868)$ of disseminated cancer. The primary outcome was major complications (death, re-operation, cardiac or neurologic events) within 30 days of surgery. Secondary outcomes included pulmonary, infectious, venous thromboembolic, and bleeding complications; prolonged length of stay; and concomitant procedures (bowel-related, cystectomy, urinary diversion, and major ureteric reconstruction). Odds ratios (OR) for each complication were calculated using univariable logistic regression.

Results: We did not identify a difference in major complication rates (OR 2.26, 95\% confidence interval [CI] 0.71-7.16). Patients with disseminated cancer had increased risk of venous thromboembolic events (OR 3.30,95\% Cl 1.04-10.48) and transfusion (OR 2.45, 95\% Cl 1.18-5.05), but similar odds of pulmonary and infectious complications and length of stay. Bowel procedures were rare, however, a significantly higher proportion of patients with disseminated cancer required bowel procedures $(2.1 \%$ vs. $0.3 \% ; p=0.03)$. Patients with disseminated cancer undergoing RP had greater comorbidities and higher predicted probability of morbidity and mortality. This study is limited by its retrospective design, lack of cancer-specific variables, and prostatectomyspecific complications.

Conclusions: RP in the context of disseminated cancer may be associated with increased perioperative complications. Caution should be exercised in embarking on this practice outside of clinical trials.

\section{Introduction}

Population-based studies from the U.S. have shown a survival benefit for patients undergoing cytoreductive radical prostatectomy (CRP) for metastatic prostate cancer (mPCa) ${ }^{1,2}$ Two large multi-institutional trials (NCT01751438, NCT00268476) evaluating this approach are underway. Nevertheless, multiple centres are currently performing CRP off-trial. ${ }^{3,4}$

Details of perioperative morbidity following CRP are sparse, limited by the retrospective nature of data collection and inherent selection and reporting biases. To date, the results of CRP from 129 patients have been reported in the literature, representing the experience from centres of excellence. ${ }^{3,4}$ Granular, systems-based, postoperative complication data, as well as the occurrence of concomitant procedures with CRP (e.g., repair of rectal injury) remain unknown.

The American College of Surgeons (ACS) National Surgical Quality Improvement Program (NSQIP) is a large, multi-institutional, validated registry that has been shown to perform better than administrative databases or institutional series in capturing intraoperative and postoperative complications. ${ }^{5-7}$ Further, it has excellent data quality owing to data abstraction directly from medical records by trained personnel $^{8,9}$ and rich data on patients' medical status to facilitate risk adjustment. Disseminated cancer status, defined as metastasis to a major organ, is collected in NSQIP and has been shown to impact perioperative outcomes, including mortality. ${ }^{10-12}$ We, therefore, sought to determine the effect of disseminated cancer on the risk of perioperative complications in patients undergoing RP for PCa. 
Satkunasivam et al.

\section{Methods}

The Sunnybrook Health Sciences Research Ethics Board approved this study, which was conducted and reported according to the recommendations of the RECORD statement. ${ }^{13}$

\section{Study subjects}

Participant use files of ACS NSQIP from January 1, 2005 to December 31, 2014 were used to identify patients undergoing open or minimally invasive RP using CPT codes (55840, 55842, and 55845 for open and 55866 for minimally-invasive) with a principal postoperative diagnosis of prostate cancer (ICD-9 code 185). We did not include perineal prostatectomy or prostatic procedures for benign prostatic hyperplasia (BPH). We identified a total of 28266 patients and then excluded 301: gender coded as "female" or "null" ( $n=94)$; missing information on important covariates $(n=154)$; missing information on length of stay $(n=1)$; and cases coded as emergent $(n=52)$.

\section{Outcomes}

The primary outcome was the occurrence of a major complication, defined as mortality, unplanned reoperation (return to the operating room [OR]), cardiac event (myocardial infarction or cardiac arrest), or neurologic event (cerebrovascular accident or coma $>24$ hours) within 30 days of surgery. Secondary outcomes included pulmonary (re-intubation or prolonged ventilation [ $>48$ hours]), infectious (including surgical site infections [superficial, deep incisional, or organ space], pneumonia, urinary tract infection, or sepsis), venous thromboembolic (deep vein thrombosis or pulmonary embolism), and bleeding complications (the requirement for one or more transfusions). Prolonged length of stay was defined as greater than two days between the date of operation and discharge, the median in this cohort.

We further characterized the operative complexity associated with RP in patients with metastatic disease by analyzing concomitant procedures, performed by the primary urological operative team or consulting surgeons. We comprehensively reviewed all concomitant procedures identified by CPT codes (Appendix A) while blinded to clinical characteristics, including disseminated cancer status. We classified concomitant procedures as bowel-related (minor and major), cystectomy (partial or complete, with or without urinary diversion), urinary diversion alone, major ureteric reconstruction, and major vascular repair (Appendix B). We did not capture surgical procedures that were concomitant but unrelated to the complexity of RP (i.e., hernia repair).

\section{Exposure}

The primary exposure was disseminated cancer at the time of RP, defined by NSQIP as a primary cancer that has metastasized to a major organ (American Joint Committee on Cancer Stage IV). ${ }^{14}$ Patients with isolated lymphatic metastases were excluded. ${ }^{14}$ A probabilistic matching algorithm linking colorectal cancer patients to the National Cancer Database showed that this variable has agreement with metastatic stage (Cohen kappa coefficient, 0.454). ${ }^{11}$

\section{Covariates}

We abstracted demographic, clinical, and operative information. Demographic information included age, race, and body mass index (BMI). Clinical data included American Society of Anesthesiology (ASA) physical status classification, cardiac disease (previous congestive heart failure, myocardial infarction, angina within 30 days, cardiovascular surgery, or percutaneous coronary intervention), neurological disease (previous cerebrovascular accident, paraplegia, hemiplegia, or quadriplegia), chronic obstructive pulmonary disease, diabetes (requiring oral agent or insulin), current smoking (active smoker within one year), chronic steroid use, and functional status prior to surgery (independent, partially dependent, totally dependent, or unknown). We also collected data on the use of minimally invasive surgical (MIS) technique.

\section{Statistical analysis}

Temporal trends in the proportion of annual cases performed on patients with disseminated cancer over time were examined using the Cochrane-Armitage test for trend..$^{15}$ Baseline demographic characteristics were examined using frequencies and proportions for categorical variables and medians and interquartile ranges (IQR) for continuous variables. We compared proportions and medians between patients with disseminated cancer and those without using the Chisquared test (Fisher's exact test, where appropriate) and Wilcoxon rank sum test, respectively.

We examined the rates of complications for each our prespecified categories and compared these for patients with and without disseminated disease using Fisher's exact test. Odds ratios (OR) and 95\% confidence intervals $(\mathrm{Cl})$ for each complication category were calculated using univariable logistic regression. We were unable to perform multivariable regression due to the lack of events.

Finally, we compared the proportions for patients undergoing a pre-specified concomitant procedure and assessed differences by disseminated cancer status using Chi-squared test and Fisher's exact test, as appropriate. 


\section{Results}

We identified 27965 patients undergoing RP who met the inclusion and exclusion criteria. Of these, 97 patients $(0.4 \%)$ had evidence of disseminated cancer at the time of surgery and 27868 (99.6\%) did not. We did not identify a statistically significant change in the proportion of patients undergoing RP who had disseminated disease over time (Cochran-Armitage trend test $\mathrm{p}=0.12$ ).

A greater proportion of patients with disseminated cancer used steroids chronically and were in ASA categories 3 and 4 (Table 1). MIS techniques were used in a lower proportion of patients with disseminated cancer (Table 1).

The NSQIP-derived probability of 30-day morbidity and mortality was available for 17921 patients in our cohort. The median estimated morbidity and mortality were higher among patients with disseminated disease $(5.7 \%, 95 \% \mathrm{Cl} 4.1-7.0 \%$ and $0.4 \%, 95 \% \mathrm{Cl} 0.2-0.7 \%$, respectively) than those without disseminated cancer $(4.3 \%, 95 \% \mathrm{Cl} 3.4-5.7 \%$ and $0.1 \%$, 95\% Cl 0.06-0.2, respectively; $\mathrm{p}<0.0001$ for each).

The primary outcome (major complications) was not different for men with disseminated disease undergoing RP (Table 2; OR 2.26, 95\% Cl 0.71-7.16) compared to those without. Similarly, perioperative mortality rates were not statistically different $(0.1 \%$ in non-disseminated and $1.0 \%$ in disseminated; $\mathrm{p}=0.09$ ). We did not identify a difference in the odds of pulmonary complications (OR $4.68,95 \% \mathrm{CI}$ 0.64-34.04), infectious complications (OR $1.05,95 \% \mathrm{Cl}$ $0.33-3.32$ ), or prolonged length of stay (OR $1.20,95 \% \mathrm{Cl}$ $0.72-2.00$ ). Median length of stay was two days (IQR 1-2 days) for patients with disseminated cancer and one day (IQR 1-2 days) for patients without disseminated cancer. Patients with disseminated cancer had increased odds of venous thromboembolic events (OR 3.30,95\% Cl 1.04-10.48) and bleeding requiring transfusion $(\mathrm{OR} 2.45,95 \% \mathrm{Cl} 1.18-5.05)$ than those without disseminated cancer.

Concomitant bowel procedures during RP were rare among all patients (Table 3). However, a significantly higher proportion of patients with disseminated cancer required bowel procedures $(2.1 \%$ vs. $0.3 \% ; p=0.03)$, cystectomy $(2.1 \%$ vs. $0.03 \% ; p=0.0006)$, and urinary diversions $(2.1 \%$ vs. $0.02 \% ; p=0.0003$ ) (Table 3 ). Ureteral reconstruction and major vascular repair were not identified among the disseminated group.

\section{Discussion}

In this study, patients undergoing RP who have disseminated cancer had greater comorbidities than those without disseminated disease and while the odds of major complications were higher, this did not reach statistical significance. We found these patients were at increased risk of receiving

\begin{tabular}{|c|c|c|c|}
\hline & $\begin{array}{c}\text { Non-disseminated } \\
n=27868\end{array}$ & $\begin{array}{c}\text { Disseminated } \\
\mathrm{n}=97\end{array}$ & p value \\
\hline Age, median (IQR) & $62.0(57.0-67.0)$ & $63.0(58.0-68.0)$ & 0.20 \\
\hline \multicolumn{4}{|l|}{ Race, n (\%) } \\
\hline Caucasian & $21,140(75.9)$ & $73(75.3)$ & \multirow{3}{*}{0.99} \\
\hline African-American & $2804(10.1)$ & $10(10.3)$ & \\
\hline Other/Unknown & $3924(14.1)$ & $14(14.4)$ & \\
\hline BMI, median (IQR) & $28.3(25.8-31.5)$ & $28.0(25.5-30.9)$ & 0.27 \\
\hline \multicolumn{4}{|l|}{ ASA category, n (\%) } \\
\hline 1 & 1072 (3.9) & $2(2.1)$ & \multirow{4}{*}{0.01} \\
\hline 2 & $17437(62.6)$ & 47 (48.5) & \\
\hline 3 & $9163(32.9)$ & $47(48.5)$ & \\
\hline 4 & $196(0.7)$ & $1(1.0)$ & \\
\hline Cardiac history, n (\%) & $658(2.4)$ & $4(4.1)$ & 0.30 \\
\hline Neurologic history, n (\%) & $210(0.8)$ & $2(2.1)$ & 0.17 \\
\hline History of COPD, n (\%) & $528(1.9)$ & $2(2.1)$ & 0.71 \\
\hline Diabetes, n (\%) & $3172(11.4)$ & $13(13.4)$ & 0.53 \\
\hline Active smoking, $\mathrm{n}(\%)$ & $3414(12.3)$ & $14(14.4)$ & 0.51 \\
\hline Chronic steroid use, n (\%) & $329(1.2)$ & $6(6.2)$ & 0.001 \\
\hline \multicolumn{4}{|l|}{ Functional status prior to surgery } \\
\hline Independent & 27735 (99.5) & $96(99.0)$ & \multirow{4}{*}{0.20} \\
\hline Partially dependent & $52(0.2)$ & $1(1.0)$ & \\
\hline Totally dependent & $2(0.01)$ & 0 & \\
\hline Unknown & $79(0.3)$ & 0 & \\
\hline Minimally invasive modality, $\mathrm{n}(\%)$ & $22874(82.1)$ & $71(73.2)$ & 0.02 \\
\hline
\end{tabular}

ASA: American Society of Anesthesiology; BMI: body mass index; COPD: chronic obstructive pulmonary disease; IQR: interquartile range. 


\begin{tabular}{|c|c|c|c|}
\hline & $\begin{array}{c}\text { Non- } \\
\text { disseminated } \\
n=27868\end{array}$ & $\begin{array}{l}\text { Disseminated } \\
\quad \mathrm{n}=97\end{array}$ & $\begin{array}{c}\mathbf{p} \\
\text { value }\end{array}$ \\
\hline Major complication, n (\%) & $389(1.4)$ & $3(3.1)$ & 0.16 \\
\hline Mortality, n (\%) & $26(0.1)$ & $1(1.0)$ & 0.09 \\
\hline Reoperation, n (\%) & $307(1.1)$ & $2(2.1)$ & 0.29 \\
\hline $\begin{array}{l}\text { Cardiac complication, } \\
\mathrm{n}(\%)\end{array}$ & $61(0.2)$ & $2(2.1)$ & 0.02 \\
\hline $\begin{array}{l}\text { Neurologic complication, } \\
\mathrm{n}(\%)\end{array}$ & $29(0.1)$ & 0 & 1.00 \\
\hline $\begin{array}{l}\text { Pulmonary complication, } \\
\mathrm{n}(\%)\end{array}$ & $62(0.2)$ & $1(1.0)$ & 0.20 \\
\hline $\begin{array}{l}\text { Infectious complication, } \\
\mathrm{n}(\%)\end{array}$ & $824(3.0)$ & $3(3.1)$ & 0.76 \\
\hline Sepsis, n (\%) & $206(0.7)$ & 0 & 1.00 \\
\hline Pneumonia, n (\%) & $70(0.3)$ & 0 & 1.00 \\
\hline $\begin{array}{l}\text { Urinary tract infection, } \\
\mathrm{n}(\%)\end{array}$ & $451(1.6)$ & $1(1.0)$ & 1.00 \\
\hline $\begin{array}{l}\text { Surgical site infection } \\
\text { (SSI), } \mathrm{n}(\%)\end{array}$ & $274(1.0)$ & $2(2.1)$ & 0.25 \\
\hline Organ space SSI, n (\%) & $108(0.4)$ & $1(1.0)$ & 0.32 \\
\hline Deep incisional SSI, n (\%) & $14(0.1)$ & $1(1.0)$ & 0.05 \\
\hline Superficial SSI, n (\%) & $154(0.6)$ & 0 & 1.00 \\
\hline $\begin{array}{l}\text { Venous thromboembolism, } \\
\mathrm{n}(\%)\end{array}$ & $267(1.0)$ & $3(3.1)$ & 0.07 \\
\hline $\begin{array}{l}\text { Deep vein thrombosis, } \\
\mathrm{n}(\%)\end{array}$ & $177(0.6)$ & $2(2.1)$ & 0.12 \\
\hline $\begin{array}{l}\text { Pulmonary embolism, } \\
\mathrm{n}(\%)\end{array}$ & $131(0.5)$ & $3(3.1)$ & 0.01 \\
\hline $\begin{array}{l}\text { Bleeding requiring } \\
\text { transfusion, } \mathrm{n}(\%)\end{array}$ & 990 (3.6) & $8(8.3)$ & 0.02 \\
\hline $\begin{array}{l}\text { Prolonged length of stay, } \\
n(\%)\end{array}$ & $4459(16.0)$ & $18(18.6)$ & 0.49 \\
\hline
\end{tabular}

concomitant bowel-related procedures $(2.1 \%$ vs. $0.3 \%)$, experiencing a venous thromboembolic event $(3.1 \%$ vs. $1.0 \%)$, and bleeding requiring a transfusion ( $8.3 \%$ vs. $3.6 \%)$.

In contrast to previous reports from institutions ${ }^{3}$ or multiinstitutional collaboratives, ${ }^{4}$ our data suggest there are specific (bowel, thrombolic, and bleeding) and potentially worse perioperative outcomes in performing RP in patients with disseminated cancer. Heidenreich et al reported a single institution series of 23 patients with low-volume mPCa that underwent RP with minimal blood loss (mean $335 \mathrm{cc}$ ) and, while two patients developed thromboembolic events, there were no Clavien Grade 4-5 complications. ${ }^{3}$ A recent multi-institutional report of $106 \mathrm{RPs}$ in patients with $\mathrm{mPCa}$ found a single case of iatrogenic ureteral injury and a $14 \%$ blood transfusion rate. ${ }^{4}$ These data from retrospective chart review likely represent highly selected patients, as evidenced by the low comorbidity scores ${ }^{4}$ compared to the generally higher comorbidities seen in our cohort of patients with disseminated cancer. Apart from patient-level factors, these excellent outcomes are also achieved through a combination of meticulous staging, case selection for surgical resectability, and expertise of each respective institution.

The use of NSQIP to extrapolate outcomes from cancer surgery has inherent limitations. While NSQIP has detailed and validated comorbidity and perioperative data, ASA classification is a somewhat crude measure of comorbidity with significant within-group heterogeneity. Further, patients with disseminated cancer may be given a higher classification on the basis of their cancer disease status, rather than their true functional status. In addition, NSQIP lacks cancer-specific variables, such as staging information, and the disseminated cancer variable does not necessarily imply that it is PCa that has metastasized. To improve this likelihood, we restricted our analysis to all men with the primary diagnosis of $\mathrm{PCa}$, although it remains possible (but unlikely) that the disseminated cancer was a secondary, metastatic malignancy. Further, NSQIP lacks pathological information (e.g., margin status), complications that are unique to prostatectomy (e.g., anastomotic leaks or lymphoceles), or grading of the severity of complications, such as the commonly used Clavien-Dindo scale. Though our report is strengthened by an extensive review of concomitant surgical procedures, we are unable to determine whether concomitant procedures were planned or imperative due to an intraoperative complication. That is, a cystectomy may be planned for palliation and local control or may be necessitated intraoperatively based on under-staging of locally advanced disease or by an intraoperative complication. Additionally, the low event rate for complications did not permit multivariable analysis to determine if disseminated cancer independently accounts for the differences observed or if there may be underlying confounders (e.g., the higher comorbidity of these patients may account for the differences observed). Lastly, the mor-

Table 3. Occurrence of concomitant or other procedures during radical prostatectomy

\begin{tabular}{|c|c|c|c|}
\hline & $\begin{array}{c}\text { Non- } \\
\text { disseminated } \\
n=27868\end{array}$ & $\begin{array}{c}\text { Disseminated } \\
\mathrm{n}=97\end{array}$ & p value \\
\hline Bowel procedures, n (\%) & $81(0.3)$ & $2(2.1)$ & 0.03 \\
\hline $\begin{array}{l}\text { Minor bowel procedures, } \\
\mathrm{n}(\%)\end{array}$ & $44(0.2)$ & $1(1.0)$ & 0.14 \\
\hline $\begin{array}{l}\text { Major bowel procedures, } \\
\mathrm{n}(\%)\end{array}$ & $40(0.1)$ & $1(1.0)$ & 0.13 \\
\hline $\begin{array}{l}\text { Cystectomy with or } \\
\text { without urinary diversion, } \\
n(\%)\end{array}$ & $9(0.03)$ & $2(2.1)$ & $<0.001$ \\
\hline Urinary diversion, $\mathrm{n}(\%)$ & $6(0.02)$ & $2(2.1)$ & $<0.001$ \\
\hline $\begin{array}{l}\text { Major ureteral } \\
\text { reconstruction, n (\%) }\end{array}$ & $110(0.4)$ & 0 & 1.00 \\
\hline $\begin{array}{l}\text { Major vascular repair, } \\
\mathrm{n}(\%)\end{array}$ & $5(0.02)$ & 0 & 1.00 \\
\hline
\end{tabular}


bidity observed with RP on univariable analysis could be attributable to performing extended pelvic lymph node dissection, as is likely done in these high-risk patients, and not necessarily the prostate extirpation itself.

Biological and mechanistic hypotheses, such as the concept of a pre-metastatic niche, have been cited in rationalizing a survival benefit from cytoreduction in $\mathrm{mPCa} .{ }^{16,17}$ However, the biological processes governing metastasis remains poorly understood and enthusiasm must be tempered by the observation that metastasis can occur from one deposit to another. ${ }^{18}$ If indeed the case, the most important space may be the oligometastatic stage and the appropriate selection of optimal candidates must be balanced with the risks of surgery.

As the landscape of PCa shifts away from early-stage can$\operatorname{cer}^{19}$ and to more advanced presentations, surgeons will face greater instances of the ethical dilemma of offering CRP outside of clinical trial settings. Taken together with the multiple barriers that surgical, randomized, controlled trials already face, particularly in accrual, a candid and cautionary consent process with patients will be required for off-trial CRP. ${ }^{20}$ The belief and bias held by surgeons that surgery is beneficial must be tempered with adequate support of other modalities, including radiation therapy in this setting. ${ }^{21}$ Our data present information that can be used in the consent process. $\mathrm{RP}$ in the setting of mPCa may be at greater perioperative risk regardless of what is driving the risk (patient factors or tumour factors). Caution should be exercised from adopting the results by centres of excellence, where selected patients appear to have adequate outcomes. Selection bias, undefined inclusion criteria, clinician-derived, subjective decision on benefit, and lastly, potential under-reporting necessitate that these reports must not be extrapolated widely.

\section{Conclusion}

$\mathrm{RP}$ in the context of disseminated cancer was associated with increased perioperative complications; however, this observation may be driven by confounders of this relationship. This investigational therapy should be considered in the context of a clinical trial wherein morbidity, as well as functional and oncological outcomes can be closely monitored.

Competing interests: The authors report no competing personal or financial interests.

Acknowledgements: The American College of Surgeons National Surgical Quality Improvement Program and the hospitals participating in the ACS NSQIP are the source of the data used herein; they have not verified and are not responsible for the statistical validity of the data analysis or the conclusions derived by the authors. Dr. Nathens is supported by the DeSouza Chair in Trauma Research. Dr. Nam is supported by the Aimera Chair of Urological Oncology.

\section{References}

1. Culp SH, Schellhammer PF, Williams MB. Might men diagnosed with metastatic prostate cancer benefit from definitive treatment of the primary tumour? A SEER-based study. Eur Urol 2014;65:1058-66. http://dx.doi.org/10.1016/i.eururo.2013.11.012

2. Satkunasivam R, Kim AE, Desai $M$, et al. Radical prostatectomy or external beam radiation therapy vs. no local therapy for survival benefit in metastatic prostate cancer: A SEER-Medicare analysis. I Urol 2015;194:378-85. http://dx.doi.org/10.1016/i.juro.2015.02.084

3. Heidenreich A, Pfister D, Porres D. Cytoreductive radical prostatectomy in patients with prostate cancer and low-volume skeletal metastases: Results of a feasibility and case-control study. J Urol 2015;193:832-8. http://dx.doi.org/10.1016/i.juro.2014.09.089

4. Sooriakumaran P, Karnes J, Stief C, et al. A multi-institutional analysis of perioperative outcomes in 106 men who underwent radical prostatectomy for distant metastatic prostate cancer at presentation. Eur Urology 2016;69:788-94. http://dx.doi.org/10.1016/i.eururo.2015.05.023

5. Davenport DL, Holsapple CW, Conigliaro J. Assessing surgical quality using administrative and clinical data sets: A direct comparison of the University HealthSystem Consortium Clinical Database and the National Surgical Quality Improvement Program data set. Am J Med Qual 2009;24:395-402. http://dx.doi. org/10.1177/1062860609339936

6. Cima RR, Lackore KA, Nehring SA, et al. How best to measure surgical quality? Comparison of the Agency for Healthcare Research and Quality Patient Safety Indicators (AHRQ-PSI) and the American College of Surgeons National Surgical Quality Improvement Program (ACS-NSQIP) postoperative adverse events at a single institution. Surgery 2011;150:943-9. http://dx.doi.org/10.1016/i.surg.2011.06.020

7. Koch CG, Li L, Hixson E, et al. What are the real rates of postoperative complications: Elucidating inconsistencies between administrative and clinical data sources. J Am Coll Surg 2012;214:798-805. http://dx.doi.org/10.1016/i.jamcollsurg.2011.12.037

8. Best WR, Khuri SF, Phelan M, et al. Identifying patient preoperative risk factors and postoperative adverse events in administrative databases: Results from the Department of Veterans Affairs National Surgical Quality Improvement Program. J Am Coll Surg 2002;194:257-66. http://dx.doi.org/10.1016/ S1072-7515(01)01183-8

9. Lawson EH, Lovie R, Zingmond DS, et al. A comparison of clinical registry vs. administrative claims data for reporting of 30-day surgical complications. Ann Surg 2012;256:973-81. http://dx.doi.org/10.1097/ SLA.0b013e31826b4c4f

10. Tseng WH, Yang X, Wang H, et al. Nomogram to predict risk of 30-day morbidity and mortality for patients with disseminated malignancy undergoing surgical intervention. Ann Surg 2011;254:333-8. http://dx.doi.org/10.1097/SLA.0b013e31822513ed

11. Merkow RP, Kmiecik TE, Bentrem DJ, et al. Effect of including cancer-specific variables on models examining short-term outcomes. Cancer 2013;119:1412-9. http://dx.doi.org/10.1002/cncr.27891

12. Hollenbeck BK, Miller DC, Taub D, et al. Risk factors for adverse outcomes after transurethral resection of bladder tumours. Cancer 2006;106:1527-35. http://dx.doi.org/10.1002/cncr.21765

13. Benchimol El, Smeeth L, Guttmann A, et al. The reporting of studies conducted using observational routinely collected health data (RECORD) statement. PLOS Med 2015;12:e1001885. http://dx.doi. org/10.1371/journal.pmed.1001885

14. ACS-NSQIP Classic, Essential, Small-Rural, Targeted and Florida Variables and Definitions. American College of Surgeons; 2012:39.

15. Armitage P. Tests for linear trends in proportions and frequencies. Biometrics 1955;11:375-86. http://dx.doi.org/10.2307/3001775

16. Kaplan RN, Rafii S, Lyden D. Preparing the "soil": The pre-metastatic niche. Cancer Res 2006;66:1108993. http://dx.doi.org/10.1158/0008-5472.CAN-06-2407

17. Kim MY, Oskarsson T, Acharyya $S$, et al. Tumour self-seeding by circulating cancer cells. Cell 2009;139:1315-26. http://dx.doi.org/10.1016/i.eell.2009.11.025

18. Gundem $G$, Van Loo $P$, Kremeyer B, et al. The evolutionary history of lethal metastatic prostate cancer. Nature 2015;520:353-7. hittp://dx.doi.org/10.1038/nature14347

19. Banerii JS, Wolff EM, Massman JD 3rd, et al. Prostate needle biopsy outcomes in the era of the U.S. Preventive Services Task Force recommendation against prostate-specific antigen-based screening. I Urol 2016;195:66-73. http://dx.doi.org/10.1016/i.juro.2015.07.099

20. Mcleod RS. Issues in surgical randomized controlled trials. World I Surg 1999;23:1210-4. http://dx.doi.org/10.1007/s002689900649

21. Parker CC, Sydes MR, Mason MD, et al. Prostate radiotherapy for men with metastatic disease: A new comparison in the Systemic Therapy in Advancing or Metastatic Prostate Cancer: Evaluation of Drug Efficacy (STAMPEDE) trial. BJU Int 2013;111:697-9. http://dx.doi.org/10.1111/bju.12087

Correspondence: Dr. Christopher J.D. Wallis, Division of Urology, Department of Surgery, Sunnybrook Health Sciences Centre, University of Toronto, Toronto, ON, Canada; wallis.jid@gmail.com 
Satkunasivam et al.

\begin{tabular}{l|}
\hline Appendix A. Procedural definitions by CPT codes \\
\hline CPT Procedure \\
\hline Lymphadenectomy \\
\hline
\end{tabular}

a) Limited pelvic lymphadenectomy

38562 Limited lymphadenectomy for staging (separate procedure); pelvic and para-aortic

38564 Limited lymphadenectomy for staging (separate procedure); retroperitoneal (aortic and/or splenic)

38570 laparoscopy, surgical with retroperitoneal lymph node sampling, single or multiple

38571 laparoscopy, surgical, with bilateral total pelvic lymphadenectomy

38589 Unlisted laparoscopy procedure, lymphatic system

38770 Pelvic lymphadenectomy, including external iliac, hypogastric, and obturator nodes (separate procedure)

38999 Unlisted procedure, hemic or lymphatic system

55842 Prostatectomy, retropubic radical, with or without nerve sparing; with lymph node biopsy(s) (limited pelvic lymphadenectomy)

b) Extended lymphadenectomy

38572 Laparoscopy, surgical; with bilateral total pelvic lymphadenectomy and peri-aortic lymph node sampling (biopsy), single or multiple

38760 Inguinofemoral lymphadenectomy, superficial, including Cloquets node (separate procedure)

38765 Inguinofemoral lymphadenectomy, superficial, in continuity with pelvic lymphadenectomy, including external iliac, hypogastric, and obturator nodes (separate procedure)

38780 Retroperitoneal transabdominal lymphadenectomy, extensive, including pelvic, aortic, and renal nodes (separate procedure)

55845 Prostatectomy, retropubic radical, with or without nerve sparing; with bilateral pelvic lymphadenectomy, including external iliac, hypogastric, and obturator nodes

Bowel procedures

\section{a) Minor bowel procedures}

44020 Enterotomy, small intestine, other than duodenum; for exploration, biopsy(s), or foreign body removal

44238 Unlisted laparoscopy procedure, intestine (except rectum)

44602 suture of small intestine (enterrhaphy) for injury

44603 Suture of small intestine (enterorrhaphy) for perforated ulcer, diverticulum, wound, injury, or rupture; multiple perforation

44604 Suture of large intestine (colorrhaphy) for perforated ulcer, diverticulum, wound, injury, or rupture; without colostomy

44605 Suture of large intestine (colorrhaphy) for perforated ulcer, diverticulum, wound, injury, or rupture; with colostomy

44620 closure of enterostomy, large or small intestine

45499 Unlisted laparoscopy procedure, rectum

45999 Unlisted procedure, rectum

\section{b) Major bowel procedures}

44110 Excision of one or more lesions of small or large intestine not requiring anastomosis, exteriorization, or fistulization; single enterotomy

44120 Enterectomy, resection of small intestine; single with anastamosis

44121 Enterectomy, resection of small intestine;

44125 Enterectomy, resection of small intestine; with enterostomy

44130 Enteroenterostomy, anastomosis of intestine, with or without cutaneous enterostomy (separate procedure)

44140 Colectomy, partial; with anastomosis

44144 Colectomy, partial; with resection, with colostomy or ileostomy and creation of mucofistula

44145 Colectomy, partial; with coloproctostomy (low pelvic anastomosis)

44187 Laparoscopy, surgical; ileostomy or jejunostomy, non-tube

44188 Laparoscopy, surgical, colostomy or skin level cecostomy

44204 Laparoscopy, surgical; colectomy, partial, with anastomosis

44205 Laparoscopy, surgical; colectomy, partial, with removal of terminal ileum with ileocolostomy

44227 Laparoscopy, surgical, closure of enterostomy, large or small intestine, with resection and anastomosis

CPT Procedure

$44310 \quad$ lleostomy or jejunostomy, non-tube

45111 Proctectomy; partial resection of rectum, transabdominal approach

45395 Laparoscopy, surgical; proctectomy, complete, combined abdominoperineal, with colostomy

45562 Exploration, repair, and presacral drainage for rectal injury 


\begin{tabular}{|c|c|}
\hline \multicolumn{2}{|c|}{ Appendix A (cont'd). Procedural definitions by CPT codes } \\
\hline \multicolumn{2}{|c|}{ Cystectomy } \\
\hline 51550 & Cystectomy, partial; simple \\
\hline 51555 & Cystectomy, partial; complicated (eg, postradiation, previous surgery, difficult location) \\
\hline 51565 & Cystectomy, partial, with reimplantation of ureter(s) into bladder (ureteroneocystostomy) \\
\hline 51570 & Cystectomy, complete; (separate procedure) \\
\hline 51575 & Cystectomy, complete; with bilateral pelvic lymphadenectomy, including external iliac, hypogastric, and obturator nodes \\
\hline 51580 & Cystectomy, complete, with ureterosigmoidostomy or ureterocutaneous transplantations; \\
\hline 51590 & Cystectomy, complete, with ureteroileal conduit or sigmoid bladder, including intestine anastomosis; \\
\hline 51595 & $\begin{array}{l}\text { Cystectomy, complete, with ureteroileal conduit or sigmoid bladder, including intestine anastomosis; with bilateral pelvic } \\
\text { lymphadenectomy, including external iliac, hypogastric, and obturator nodes }\end{array}$ \\
\hline 51596 & $\begin{array}{l}\text { Cystectomy, complete, with continent diversion, any open technique, using any segment of small and/or large intestine to } \\
\text { construct neobladder }\end{array}$ \\
\hline \multicolumn{2}{|c|}{ Urinary diversion } \\
\hline 50815 & Ureterocolon conduit, including intestine anastomosis \\
\hline 50820 & Ureteroileal conduit (ileal bladder), including intestine anastomosis (Bricker operation) \\
\hline 50825 & $\begin{array}{l}\text { Continent diversion, including intestine anastomosis using any segment of small and/or large intestine (Kock pouch or Camey } \\
\text { enterocystoplasty) }\end{array}$ \\
\hline 50845 & Cutaneous appendico-vesicostomy \\
\hline 50860 & Ureterostomy, transplantation of ureter to skin \\
\hline \multicolumn{2}{|c|}{ Major ureteral reconstruction } \\
\hline 50605 & Ureterotomy for insertion of indwelling stent, all types \\
\hline 50715 & Ureterolysis, with or without repositioning of ureter for retroperitoneal fibrosis \\
\hline 50760 & Ureteroureterostomy \\
\hline 50780 & Ureteroneocystostomy; anastomosis of single ureter to bladder \\
\hline 50782 & Ureteroneocystostomy; anastomosis of duplicated ureter to bladder \\
\hline 50783 & Ureteroneocystostomy; with extensive ureteral tailoring \\
\hline 50785 & Ureteroneocystostomy; with vesico-psoas hitch or bladder flap \\
\hline 50840 & Replacement of all or part of ureter by intestine segment, including intestine anastomosis \\
\hline 50900 & Ureterorrhaphy, suture of ureter (separate procedure) \\
\hline 50770 & Transureteroureterostomy, anastomosis of ureter to contralateral ureter \\
\hline 50947 & Laparoscopy, surgical; ureteroneocystostomy with cystoscopy and ureteral stent placement \\
\hline 50948 & Laparoscopy, surgical; ureteroneocystostomy without cystoscopy and ureteral stent placement \\
\hline 50949 & Unlisted laparoscopy procedure, ureter \\
\hline \multicolumn{2}{|c|}{ Major vessel repair } \\
\hline 35221 & Repair blood vessel, direct; intra-abdominal \\
\hline 35226 & Repair blood vessel, direct; lower extremity \\
\hline 35251 & Repair blood vessel with vein graft; intra-abdominal \\
\hline 35256 & Repair blood vessel with vein graft; lower extremity \\
\hline 35281 & Repair blood vessel with graft other than vein; intra-abdominal \\
\hline 35286 & Repair blood vessel with graft other than vein; lower extremity \\
\hline
\end{tabular}

\begin{tabular}{lll}
\hline Appendix B. Classification of concomitant procedures \\
\hline \multicolumn{2}{c}{ Concomitant procedure } & Description \\
\hline 1 & $\begin{array}{l}\text { Lymphadenectomy categorized as "not } \\
\text { performed," "limited pelvic," or "extended" }\end{array}$ & $\begin{array}{l}\text { Noting that receipt of lymphadenopathy is captured as part of the primary CPT } \\
\text { code, the intent of this variable was to explore occurrence of extended template } \\
\text { lymphadenectomy and not necessarily capture the receipt of lymph node dissection. }\end{array}$ \\
2 & $\begin{array}{l}\text { Bowel-related procedures, including small } \\
\text { and large bowel resection, repair or diversion }\end{array}$ & $\begin{array}{l}\text { This was further sub-divided into minor bowel procedure (bowel repair) and major } \\
\text { bowel procedure (bowel resection or diversion). }\end{array}$ \\
3 & Cystectomy & $\begin{array}{l}\text { Includes partial or complete. } \\
\text { Includes any form (continent or incontinent) urinary diversion. }\end{array}$ \\
4 & Urinary diversion & $\begin{array}{l}\text { Ureteric re-implantation, uretero-ureterostomy, ureterostomy for stent insertion, } \\
\text { ureteric replacement with bowel segment, or ureteric repair. We excluded cystoscopy } \\
\text { and ureteric stent insertion, as this may represent a planned preoperative maneuver } \\
\text { and does not overall result in significant patient morbidity. }\end{array}$ \\
& Direct repair of major vessels or replacement with vein or other graft.
\end{tabular}

